\title{
Cigarette smoke exposure impairs $\beta$-cell function through activation of oxidative stress and ceramide accumulation
}

\author{
Xin Tong ${ }^{2,9}$, Zunaira Chaudhry ${ }^{1,9}$, Chih-Chun Lee ${ }^{1}$, Robert N. Bone ${ }^{1}$, Sukrati Kanojia ${ }^{1}$, Judith Maddatu ${ }^{1}$, \\ Paul Sohn ${ }^{1,6}$, Staci A. Weaver ${ }^{1,7}$, Morgan A. Robertson ${ }^{3}$, Irina Petrache ${ }^{4, * *}$, \\ Carmella Evans-Molina ${ }^{1,5,6,7,8, * * *}$, Tatsuyoshi Kono ${ }^{1,5, *}$
}

\section{ABSTRACT}

Objectives: Epidemiological studies indicate that first- and second-hand cigarette smoke (CS) exposure are important risk factors for the development of type 2 diabetes (T2D). Additionally, elevated diabetes risk has been reported to occur within a short period of time after smoking cessation, and health risks associated with smoking are increased when combined with obesity. At present, the mechanisms underlying these associations remain incompletely understood. The objective of this study was to test the impact of CS exposure on pancreatic $\beta$-cell function using rodent and invitromodels.

Methods: Beginning at 8 weeks of age, C57BL/ $6 \mathrm{~J}$ mice were concurrently fed a high-fatdiet (HFD) and exposed to CS for 11 weeks, followed by an additional 11 weeks of smoking cessation with continued HFD. Glucose tolerance testing was performed during CS exposure and during the cessation period. Cultured INS-1 $\beta$-cells and primary islets were exposed ex vivo to CS extract (CSE), and $\beta$-cell function and viability were tested. Since CS increases ceramide accumulation in the lung and these bioactive sphingolipids have been implicated in pancreatic $\beta$-cell dysfunction in diabetes, islet and $\beta$-cell sphingolipid levels were measured in islets from CS-exposed mice and in CSE-treated islets and INS-1 cells using liquid chromatography-tandem mass spectrometry.

Results: Compared to HFD-fed, ambient air-exposed mice, HFD-fed and CS-exposed mice had reduced weight gain and better glucose tolerance during the active smoking period. Following smoking cessation, CS-mice exhibited rapid weight gain and had accelerated worsening of their glucose tolerance. CS-exposed mice had higher serum proinsulin/insulin ratios, indicative of $\beta$-cell dysfunction, significantly lower $\beta$-cell mass $(p=0.017)$, reduced $\beta$-cell proliferation $(p=0.006)$, and increased islet ceramide content compared to non-smoking control mice. Ex vivo exposure of isolated islets to CSE was sufficient to increase islet ceramide levels, which was correlated with reduced insulin gene expression and glucose-stimulated insulin secretion, and increased $\beta$-cell oxidative and endoplasmic reticulum (ER) stress. Treatment with the antioxidant Nacetylcysteine markedly attenuated the effects of CSE on ceramide levels, restored $\beta$-cell function and survival, and increased cyclin D2 expression, while also reducing activation of $\beta$-cell ER and oxidative stress.

Conclusions: Our results indicate that CS exposure leads to impaired insulin production, processing, secretion and reduced $\beta$-cell viability and proliferation. These effects were linked to increased $\beta$-cell oxidative and ER stress and ceramide accumulation. Mice fed HFD continued to experience detrimental effects of CS exposure even during smoking cessation. Elucidation of the mechanisms by which CS exposure impairs $\beta$-cell function in synergy with obesity will help design therapeutic and preventive interventions for both active and former smokers.

(c) 2020 The Authors. Published by Elsevier GmbH. This is an open access article under the CC BY-NC-ND license (http://creativecommons.org/licenses/by-nc-nd/4.0/).

Keywords Ceramide; Smoking; Insulin secretion; 0xidative stress; $\beta$-cell; Type 2 diabetes

\footnotetext{
${ }^{1}$ Department of Medicine, Indiana University School of Medicine, Indianapolis, IN, USA ${ }^{2}$ Department of Molecular Physiology and Biophysics, Vanderbilt University, Nashville, TN, USA ${ }^{3}$ Indiana Bioscience Research Institute, Indianapolis, IN, USA ${ }^{4}$ Division of Pulmonary and Critical Care Medicine, Department of Medicine, National Jewish Health, Denver, CO, USA ${ }^{5}$ Richard L. Roudebush VA Medical Center, Indianapolis, IN, USA ${ }^{6}$ Department of Cellular and Integrative Physiology, Indiana University School of Medicine, Indianapolis, IN, USA ${ }^{7}$ Department of Biochemistry and Molecular Biology, Indiana University School of Medicine, Indianapolis, IN, USA ${ }^{8} \mathrm{Herman} B$ Wells Center for Pediatric Research, Indiana University School of Medicine, Indianapolis, IN, USA

9 These authors contributed equally to this work.

*Corresponding author. Indiana University School of Medicine, 635 Barnhill Drive, MS 2031A, Indianapolis, IN, 46202, USA. Tel.: +317 274 4145; fax 3172744107 . Email: konot@iu.edu (T. Kono).

***Corresponding author. Department of Medicine, Indiana University School of Medicine, Indianapolis, IN, USA. E-mail: cevansmo@iu.edu (C. Evans-Molina).

**Corresponding author. 1400 Jackson St, Denver, CO, 80806, USA. Tel.: +303 270 2080. E-mail: Petrachel@NJHealth.org (I. Petrache).
}

Received August 29, 2019 • Revision received March 3, 2020 • Accepted March 6, 2020 • Available online 13 March 2020

https://doi.org/10.1016/j.molmet.2020.100975 


\begin{tabular}{|c|c|c|c|}
\hline \multirow{2}{*}{\multicolumn{2}{|c|}{ List of abbreviations }} & $\mathrm{ITT}$ & Insulin tolerance test \\
\hline & & LC-MS/MS & Liquid chromatography-tandem mass spectrometry \\
\hline ASAH1 & $\mathrm{N}$-acylsphingosine amidohydrolase 1 & NAC & n-acetylcysteine \\
\hline AUC & Area under the curve & NS & Non-smoking control \\
\hline \multirow{3}{*}{\multicolumn{2}{|c|}{$\begin{array}{c}\text { BiP/GRP78/HSPA5 } \text { Binding immunoglobulin protein, Glucose } \\
\text { regulated protein } 78 \mathrm{kD} \text {, Heat-Shock } \\
70 \mathrm{kD} \text { protein } 5\end{array}$}} & Nrf2 & Nuclear factor erythroid 2-related factor 2 \\
\hline & & OCR & Oxygen consumption rate \\
\hline & & $\mathrm{PC} 1 / 3$ & Proprotein convertase $1 / 3$ \\
\hline $\mathrm{CHOP}$ & CCAAT/enhancer-binding protein homologous protein & $\mathrm{p} 21$ & cyclin-dependent kinase inhibitor p21 \\
\hline CS & Cigarette smoke & S1P & sphingosine-1-phosphate \\
\hline CSE & Cigarette smoke extract & SPT1 & serine palmitoyltransferase 1 \\
\hline \multicolumn{2}{|c|}{ DH-Ceramide dihydroceramide } & SMPD & sphingomyelin phosphodiesterase \\
\hline ER & endoplasmic reticulum & SPHK & Sphingosine Kinase \\
\hline FCCP & Carbonyl cyanide 4-(trifluoromethoxy) phenylhydrazone & S0D1 & Superoxide dismutase 1 \\
\hline GPX1 & Glutathione Peroxidase 1 & UGCG & Ceramide glucosyltransferase \\
\hline GTT & Glucose tolerance test & $\mathrm{T} 2 \mathrm{D}$ & Type 2 diabetes \\
\hline HFD & High-fat diet & Xbp-1 & X-box binding protein 1 \\
\hline Hsp30 & Heat-Shock protein $30 \mathrm{kD}$ & & \\
\hline
\end{tabular}

\section{INTRODUCTION}

Worldwide, diabetes and cigarette smoking are highly prevalent public health concerns. Type 2 diabetes (T2D) impacts over 422 million individuals, and more than 1.1 billion individuals actively smoke $[1,2]$. More strikingly, nearly 1.9 billion individuals are exposed second hand to cigarette smoke (CS) [3]. While a number of genetic risk variants for T2D have been identified through genome wide association studies, lifestyle factors such as nutrition, physical activity, and potential chemical and environmental exposures are thought to strongly influence diabetes susceptibility. Epidemiological studies indicate that CS exposure is an important risk factor for the development of T2D, and diabetes risk remains heightened even after smoking cessation $[4,5]$. Thus, first and second hand smoke exposure represent important modifiable risk factors for the development of T2D in a potentially large pool of at-risk individuals [6,7].

Human physiologic studies suggest that CS exposure impairs peripheral insulin sensitivity and pancreatic $\beta$-cell function, despite a link to reduced body weight [8-10]. In addition, individual cohort studies have shown that within $1-5$ years after smoking cessation, subjects with a previous smoking history had a $22-91 \%$ higher incidence of developing T2D [11,12], and this increased risk was correlated to weight gain after cessation of tobacco use [13]. At present, the mechanisms underlying impaired glucose homeostasis in response to cigarette smoke exposure, especially a full understanding of the effects of smoking on pancreatic $\beta$-cell function, remain unknown.

To address this knowledge gap, we developed a rodent model of CS exposure coupled with a high-fat diet (HFD) to mimic the combined effects of CS and diet-induced obesity. To provide insight into the mechanisms of smoking induced $\beta$-cell dysfunction, analysis of this rodent model was combined with an in vitro model where cultured $\beta$-cells and primary rodent islets were exposed to CS extract (CSE). Exposure to CSE, derived from smoke condensate followed by removal of particulate matter, has been extensively used in ex vivo models [14-18]. Previous studies have reported a significant increase in ceramide in the lung and other tissues after experimental exposure to CS [18-20], so we also tested whether CS-exposure influenced $\beta$-cell ceramide content. In our in vivo model, the combination of CS exposure and HFD caused rapid weight gain in mice and increased $\beta$-cell ceramide levels during the immediate cessation period. Smoking-induced ceramide accumulation in $\beta$-cells was correlated with impaired $\beta$-cell function, reduced $\beta$-cell mass and proliferation, and impaired insulin secretion and processing. These effects were largely recapitulated in our in vitro model of CSE-exposed $\beta$-cells and islets, where we observed increased ceramide levels, reduced insulin secretion, and reduced $\beta$-cell survival. The antioxidant NAC reversed the in vitro effects of CSE exposure and prevented excessive ceramide accumulation, suggesting a primary role for oxidative stress in smokinginduced $\beta$-cell dysfunction.

\section{MATERIALS AND METHODS}

\subsection{Animals and metabolic studies}

Male C57BL/6 J mice were obtained from Jackson Laboratories (Bar Harbor, ME) at 7 weeks of age and maintained under protocols approved by the Indiana University School of Medicine Institutional Animal Care and Use Committee in accordance with guidelines from the Association for Assessment and Accreditation of Laboratory Animal Care. Mice were fed a high-fatdiet (HFD) containing $45 \%$ of kilocalories from fat (D12451, Research Diets Laboratories, New Brunswick, NJ), beginning at 8 weeks of age and were maintained on a standard lightdark cycle with ad libitum access to HFD and water. In parallel with HFD initiation, mice were exposed to CS using 3R4F research grade cigarettes (Kentucky Tobacco Research and Development Center, University of Kentucky, Lexington, KY), with $11 \%$ mainstream and $89 \%$ side-stream smoke or ambient air control for $5 \mathrm{~h}$ a day, 5 days a week for a total of 11 weeks, using the Teague $10 \mathrm{E}$ whole body exposure apparatus (Figure 1A) [21]. Intraperitoneal glucose tolerance tests (GTT) were performed after $6 \mathrm{~h}$ of fasting followed by the administration of glucose at a dose of $2 \mathrm{~g} / \mathrm{kg}$ total body weight. Insulin tolerance tests (ITT) were performed after $3 \mathrm{~h}$ of fasting and administration of recombinant human insulin from Boehringer Ingelheim Vetmedica (Duluth, GA) at a dose of $0.75 \mathrm{IU} / \mathrm{kg}$ total body weight. Glucose levels were measured using the AlphaTRAK glucometer (Abbott Laboratories, Abbott Park, IL). Serum insulin and proinsulin levels were measured using ELISAs from Mercodia (Salem, NC) and ALPCO Diagnostics (Salem, NH), respectively. Dual X-ray Absorptiometry (DEXA) analysis was performed to estimate body composition using the Lunar PIXImus II (GE Medical Systems) as previously described [22]. 
A

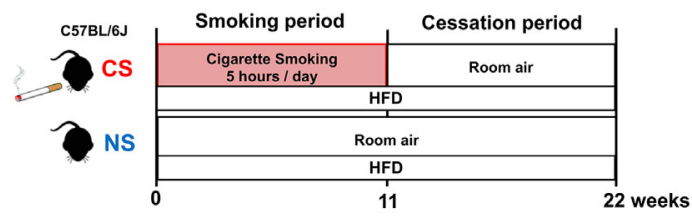

E

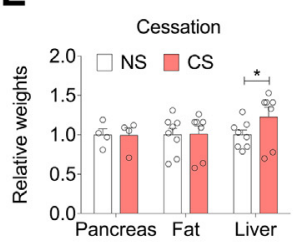

J

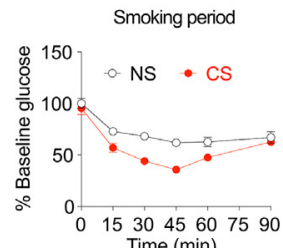

F

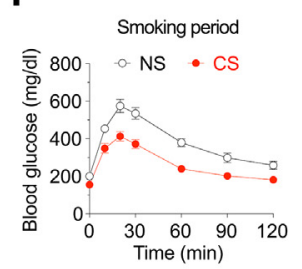

K

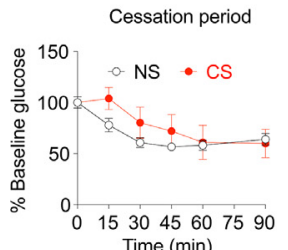

B

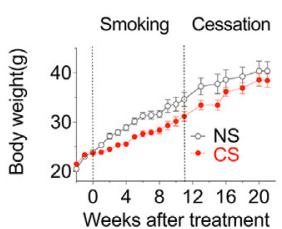

G

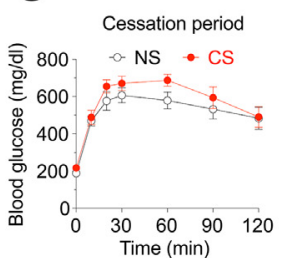

L

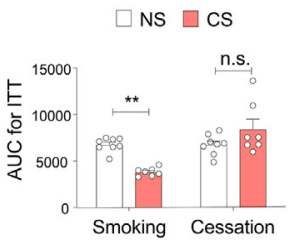

C

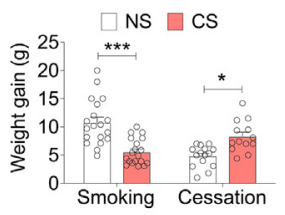

H

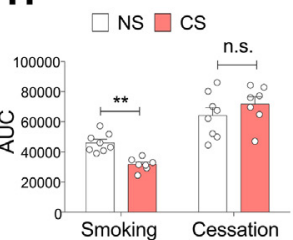

I

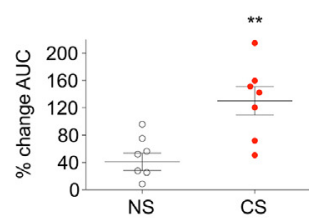

M

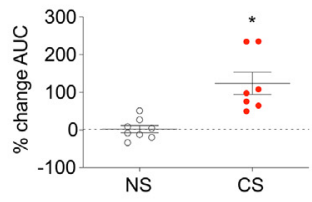

Figure 1: CS exposure increased weight gain and worsened glucose tolerance after smoking cessation in HFD-fed C57BL/6J mice. (A) Schematic of study design. Non-smoking (NS) and Cigarette Smoke (CS) groups were fed a high-fat diet (HFD) containing $45 \%$ of kilocalories from fat for 22 wks. CS mice were placed in a smoking chamber for $5 \mathrm{~h}$ /day for 5 days per week for the first 11 weeks. NS mice were exposed to room air. After 11 weeks, both NS and CS groups continued for an additional 11 weeks on HFD with standard housing conditions. (B) Results of weekly body weight measurements for 0-22 weeks of the study. (C) Body weight gain during the smoking and cessation periods. (D-E) Body lean/fat mass and weights of whole pancreas, liver, and epididymal fat pads were compared between the groups at the end of the study. (F-G, J-K) Glucose tolerance tests (GTT) and insulin tolerance tests (ITT) were performed during the smoking period (week 9-11) and the cession period (week 20-22). (H, L) Area Under Curve (AUC) for GTT and ITT data was quantified. (I, M) Percentage (\%) change of AUC during the cessation period (week 20-22 minus week 9-11/week 9-11) was analyzed for each group. Data for individual animals are indicated by the open circles; $\mathrm{n}=8-15$. Results are displayed as the means $\pm \mathrm{S} . \mathrm{E} . \mathrm{M}$; ${ }^{*} \mathrm{p}<0.05,{ }^{* *} \mathrm{p}<0.01,{ }^{* * *} \mathrm{p}<0.001$ compared to non-smoking group (NS) or indicated comparisons.

\subsection{Immunohistochemistry and immunofluorescence}

Pancreata were rapidly removed following euthanasia and fixed overnight using Z-fix buffered zinc formalin fixative (Anatech Ltd., Battle Creek, Ml), followed by paraffin embedding and longitudinal sectioning at $5 \mu \mathrm{m}$ intervals, as previously described [22]. $\beta$-cell proliferation was assessed as detailed in previous publications [23]. $\beta$-cell mass was estimated for each animal by determining the average $\beta$-cell surface area multiplied by the pancreatic weight, as previously described [23,24]. A total of 13 mice were analyzed for $\beta$-cell mass, and $4-5$ sections, at least $50 \mu \mathrm{m}$ apart, per animal were stained and analyzed using Zen Blue software (Carl Zeiss, Jena, Germany).

\subsection{Glucose-stimulated insulin secretion (GSIS), quantitative real- time PCR (qRT-PCR) and immunoblot}

Mouse pancreatic islets were isolated by collagenase digestion, and INS-1 832/13 rat insulinoma cells were cultured as previously described [25]. Static GSIS, qRT-PCR, and immunoblot analysis were performed using previously published methods [26]. Islet perifusionbased secretory profiles was measured using the Biorep Perifusion System (Biorep, Miami Lakes, FL). Twenty-four hours after isolation, 50 handpicked islets were loaded into each perifusion chamber; islets were perifused with Krebs buffer containing $2.8 \mathrm{mmol} / \mathrm{L}$ glucose for $20 \mathrm{~min}$, followed by $16.7 \mathrm{mmol} / \mathrm{L}$ glucose for $40 \mathrm{~min}$ at a rate of $120 \mu \mathrm{L} / \mathrm{min}$. Secreted insulin was measured using ELISA (Mercodia); results were normalized to total DNA content. The following primary antibodies were employed at the indicated dilutions: anti-total caspase-3 rabbit antibody, which detected both cleaved and total caspase-3 (1:1000, Cell Signaling, Danvers, MA); anti-PC1/3 rabbit antibody (1:1000, Cell Signaling); anti-Cyclin D2 rabbit antibody (1:1000, Santa Cruz Biotechnology, Santa Cruz, CA), and anti-Actin mouse antibody (1:10,000, MP Bioscience, Santa Ana, CA).

\subsection{Cigarettes smoke extract (CSE) preparation and cell-based studies}

Aqueous CSE was obtained from research-grade cigarettes (3R4F) purchased from the Kentucky Tobacco Research and Development Center (University of Kentucky, Lexington, $\mathrm{KY}$ ) as previously described [18]. In brief, air control (AC) or CSE stock (100\%) extract were prepared by bubbling ambient air or smoke from two cigarettes into $20 \mathrm{ml}$ of PBS at a rate of 1 cigarette/minute, followed by $\mathrm{pH}$ adjustment to 7.4, and $0.2 \mu \mathrm{m}$ filtration. Cell and islet treatments were performed using CSE or AC extract concentrations ranging from $1 \%$ to $10 \%$ (vol:vol). To adjust the variation of potency of CSE from different lots, we performed titration tests for cell viability measuring ATP levels with CellTiter-Glo Luminescent Cell Viability Assay (Promega, Madison, WI). We determined a lethal concentration defined as $50 \%$ death after $24 \mathrm{~h}$ treatment (LC50) and used this concentration for CSE treatment. For propidium iodide (PI) staining, INS-1 cells were dissociated with trypsin-EDTA, followed by $70 \%$ ethanol fixation. Cells were then washed with PBS and incubated at $37{ }^{\circ} \mathrm{C}$ for $40 \mathrm{~min}$ in $50 \mu \mathrm{g} / \mathrm{ml} \mathrm{PI}$ solution. Imaging cytometry analysis was performed using the CellometerTM K2 (Nexcelom Bioscience, Lawrence, MA). CellTiter-Glo 
Luminescent Cell Viability Assay (Promega, Madison, WI) and Earlytox live/dead assay kit (Molecular Devices, San Jose, CA) were used for studies of INS-1 cells treated with CSE or AC extract with or without $5 \mathrm{mM}$ N-Acetyl Cysteine (NAC) from Invitrogen; Thermo Fisher Scientific, Inc (Waltham, MA) and tauroursodeoxycholic acid (TUDCA) from Cayman Chemical (Ann Arbor, Ml) coincubation for $24 \mathrm{~h}$.

\subsection{Analysis of sphingolipids by LC-MS/MS}

To profile sphingolipids in isolated mouse islets or INS-1 cells, lipid extraction and liquid chromatography-tandem mass spectrometry (LCMS/MS) were performed according to detailed methods published previously [19]. The MS system was a Sciex 6500 QTRAP mass spectrometer interfaced with a Shimadzu Nexiera X2 UHPLC system. Sphingolipids were ionized via electrospray ionization (ESI) with detection via multiple reaction monitoring (MRM). Analysis of sphingoid bases and the molecular species of ceramides employed ESI in positive ions with MRM analysis. C17-sphingosine and $\mathrm{N}-\mathrm{C} 17$-ceramide were used as the internal standards.

\subsection{Analysis of mitochondrial respiration}

The Seahorse Extracellular Flux Analyzer XFe96 (Agilent Technologies) and Mito Stress Test (Agilent Technologies cat\# 103,015) were utilized to measure mitochondrial respiration in INS-1 cells treated with AC, CSE or CSE + NAC for $20 \mathrm{~h}$. Cells were incubated in pre-warmed assay media at a pH of 7.4 (Agilent Technologies 103,576-100) that had supplemented with $11 \mathrm{mM}$ glucose, $2 \mathrm{mM}$ L-glutamine and $1 \mathrm{mM}$ pyruvate in a non- $\mathrm{CO}_{2}$ incubator at $37^{\circ} \mathrm{C}$ for $1 \mathrm{~h}$ prior to the assay. Mito Stress Test assay compounds, Oligomycin $(2.0 \mu \mathrm{M})$, FCCP [Carbonyl cyanide 4-(trifluoromethoxy) phenylhydrazone] (3.0 $\mu \mathrm{M})$, and Rotenone/Antimycin $(1.0 \mu \mathrm{M})$ were diluted in assay media and sequentially added to the cells at $\sim 15 \mathrm{~min}, \sim 34 \mathrm{~min}$, and $\sim 54 \mathrm{~min}$, respectively. 0xygen consumption readings were taken every $6.5 \mathrm{~min}$ for a total of three readings prior to and after each injection of compound. Oxygen consumption rates (OCR) were normalized by total cell count per well. Cells in each well were counted using phase-contrast and cell masking on the IncucyteS3 imaging platform using a $10 \times$ objective and autofocus capability.

\subsection{Statistical analysis}

Differences between groups were analyzed for significance using unpaired Student's $t$ test or one-way analysis of variance with Tukey-Kramer post hoc analysis. Results are displayed as the means \pm S.E.M. Data were analyzed using GraphPad Prism software (GraphPad Software, La Jolla, $C A$ ) and a $p$ value $<0.05$ was taken to indicate the presence of a significant difference between experimental groups.

\section{RESULTS}

\subsection{CS exposure followed by smoking cessation increased weight} gain and worsened glucose tolerance in mice

C57BL/6 J mice were exposed to an initial phase of 11 weeks of CS exposure (for $5 \mathrm{~h} /$ day; 5 days per week) combined with 45\% HFD, which closely mimics a high-fat Western diet [27]. This was followed by smoking cessation and continued HFD exposure for an additional 11 weeks (Fig. 1A). Control mice (NS) were maintained under normal ambient air control conditions combined with a $45 \%$ HFD for the entire 22-week treatment period.

During the active smoking period, CS-exposed mice had reduced body weight compared to the NS group, but their rate of weight gain increased during the smoking cessation period (Figure 1B-C), such that by the end of the 22-week experiment, total body weight (Fig. 1B), lean mass, and fat mass (Fig. 1D) were similar between the groups. Whole pancreas, liver, and epididymal fat weights were analyzed, and only liver weights were significantly higher in the CS-exposed group at week 22 (Figure 1D-E).

Concordant with the observed patterns of total body weight change, glucose tolerance in CS-exposed mice at 11 weeks was better than that of HFD-mice maintained under control air conditions. Although the differences of absolute GTT responses between the groups at the end of the 22-week observation period did not reach statistical significance (Figure $1 \mathrm{~F}-\mathrm{H}$ ), when analyzed as the $\%$ change in the area under the curve (AUC) from 11 to 22 weeks, CS-exposed mice exhibited a significantly higher \% change during smoking cessation (Fig. 1I). In addition, insulin sensitivity of the CS-exposed group was higher during the smoking period, followed by marked worsening during the smoking cessation period (Figure $1 \mathrm{~J}-\mathrm{L}$ ). Similar to the glucose tolerance trend, the CS group animals had a significantly higher \% change in the AUC of the ITT response from 11 to 22 weeks (Fig.1M).

\subsection{CS reduced insulin processing, $\beta$-cell mass, and $\beta$-cell} proliferation during the smoking cessation period in C57BL/6 J mice To define the origins of the failed adaptive response to HFD observed during the smoking cessation period, we analyzed insulin processing capacity, $\beta$-cell mass and $\beta$-cell proliferation in CS-exposed and NS mice. Elevations in the serum proinsulin/insulin ( $\mathrm{PI} / \mathrm{I})$ ratio are observed in humans with both $\mathrm{T} 1 \mathrm{D}$ and $\mathrm{T} 2 \mathrm{D}$ and reflect a reduced ability to complete processing of proinsulin to mature insulin arising within the context of increased $\beta$-cell stress [4]. At 22 weeks, the $\mathrm{PI} / \mathrm{I}$ ratio in serum was increased in the CS-exposed group compared to NS controls (Figure $2 \mathrm{~A}-\mathrm{C}$ ). In addition, analysis of $\beta$-cell mass revealed a significant reduction ( $3.00 \mathrm{mg}$ vs. $2.21 \mathrm{mg}, \mathrm{p}=0.00167$ ) in CSexposed mice (Figure 2D-E). Consistent with this finding, $\beta$-cell proliferation, which was determined by quantification of proliferating cell nuclear antigen (PCNA) and insulin co-staining, was reduced in CS-exposed mice compared to control mice $(p=0.006)$ (Fig. 2F).

\subsection{CS exposure increased ceramide accumulation in pancreatic} islets during the smoking cessation period

Next, using tandem mass spectrometry, we measured ceramide levels in isolated islets from mice exposed to CS before and following smoking cessation. At week 11, CS exposure was associated with modest reductions in ceramides compared to control mice, mostly in palmitoyl (C16:0)- and behenic (C22:0)- ceramide species. In contrast, islets from CS-exposed mice isolated at 16 weeks exhibited marked increases in multiple species, including stearic (C18:0)-, arachidic (C20:0)-, docosanoid-, and the saturated and monounsaturated lignoceric (C24:0 and C24:1)- ceramides (Figure 3B).

\subsection{CSE treatment increased ceramides and related metabolites in} INS-1 cells and isolated mouse islets

Islets could be directly affected by soluble components of CS that cross the alveolar-capillary lung barrier and are distributed to tissues via the circulation. Alternatively, they could be injured by mediators released by other CS-activated cells in a paracrine or autocrine manner [28,29]. To determine whether direct CS exposure was itself sufficient to cause islet dysfunction and increase ceramide levels, we exposed cultured $\beta$ cells and mouse islets to CSE ex vivo. We used culture medium containing $10 \% \mathrm{FBS}$, which contains $\sim 50 \mu \mathrm{M}$ total free fatty acids and $15 \mu \mathrm{M}$ palmitate, capable of serving as precursors for de novo ceramide synthesis. In both models, CSE exposure for $24 \mathrm{~h}$ resulted in a marked increase in multiple ceramide species. Compared to controltreated cells, CSE-treatment increased ceramides in INS-1 cells 
A

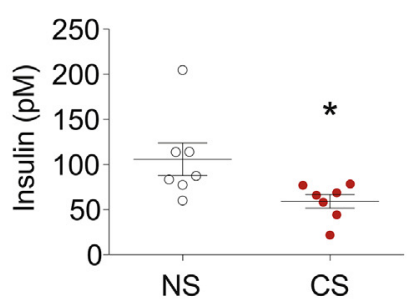

D

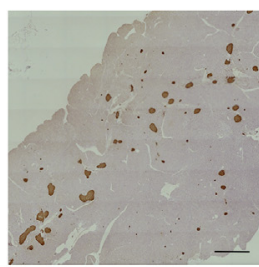

NS
B

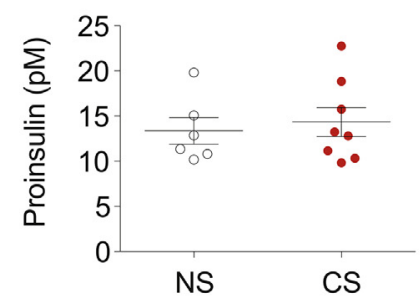

E

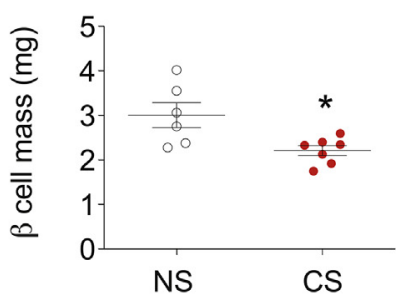

C



$\mathbf{F}$

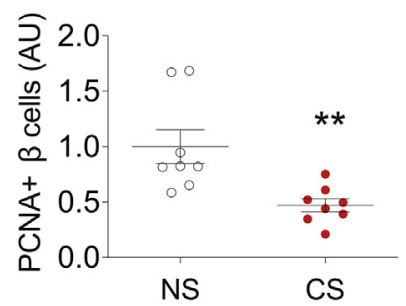

Figure 2: CS reduced insulin processing, $\beta$-cell mass, and $\beta$-cell proliferation during the smoking cessation period in C57BL/6J mice. Following the study design depicted in Figure $1 \mathrm{~A}$, the capacity for insulin production was evaluated in NS and CS mice at the study endpoint of 22 weeks. (A-C) Blood was collected from random fed mice and serum levels of insulin, proinsulin, and the ratios of proinsulin to insulin were determined by ELISA. (D-F) The mass of insulin positive cells and the number of proliferating $\beta$-cells within pancreata of study mice were quantified in paraffin tissue sections by immunostaining for insulin and the proliferative marker PCNA. Data for individual mice in each group are indicated by the circles. Results are displayed as the means \pm S.E.M; ${ }^{*} p<0.05, * * p<0.01$ compared to non-smoking (NS) group.

ranging from $\sim 1.4$ fold (palmitoyl- and stearic-ceramides) to more than 1.7-fold (behenic- and lignoceric-ceramides) (Figure 4A). Ceramides were increased to an even greater extent in CSE-exposed islets, with most species being increased by more than 3-fold compared to control conditions (Figure 4A-D). Mass spectrometric measurements of other related sphingolipid metabolites revealed increases in both precursors of ceramide in the de novo sphingolipid synthesis pathway (DH-sphingosine and DH-ceramide (Figure 4B-D) and, in the case of isolated islets, sphingosine (Fig. 4D), which is an immediate downstream ceramide metabolite produced by ceramidase.

\subsection{Exposure to CSE reduced insulin secretion and increased activation of $\beta$-cell ER stress and oxidative stress signaling pathways}

Results from our in vivo model showed that serum insulin levels were lower in mice exposed to CS. To test directly the impact of CSE on insulin secretion and production, insulin expression was measured and glucose-stimulated insulin secretion (GSIS) assays were performed in INS-1 cells exposed to CSE for $24 \mathrm{~h}$. GSIS was significantly reduced (284.5 vs $115.2 \mu \mathrm{U} / \mathrm{ml} / \mathrm{mg}$ protein, $\mathrm{p}=0.005$ ) in CSE-exposed INS-1 cells versus control cells (Figure $5 \mathrm{~A}$ ). In addition, mature and pre-insulin mRNA levels were reduced by $70.1 \%$ and $68.7 \%$, respectively, in CSEexposed cells (Figure $5 B-D$ ), indicating a defect in insulin gene transcription as well as a reduction in total levels of mature insulin mRNA. Because both elevations in the proinsulin/insulin ratio, reduced insulin expression, and ceramides have been linked with activation of $\beta$-cell oxidative stress and ER stress [18], we next quantified the expression of genes involved in these processes. Results from this analysis indicated a global increase in the expression of genes involved in oxidative stress (Nrf2, Sod1, and Gpx1) and ER stress signaling (Bip, CHOP, Hsp30, and spliced/total $X b p-1$ ) (Figure $5 \mathrm{G}-\mathrm{H}$ ). Consistent with these findings, live/ dead analysis showed that $\beta$-cell survival was reduced by $\sim 41.5 \%$


Figure 3: CS exposure increased ceramide accumulation in pancreatic islets following smoking cessation. The study design of Figure $1 \mathrm{~A}$ was executed and pancreatic islets were isolated during the last week of the smoking period $(A)$ and 5 weeks after smoking cessation $(B)$. The concentrations of six different ceramide species were determined by LC-MS/MS and are shown as relative levels. Each sample has a total 200 islets pooled from two mice. The replicates for each experimental group are indicated by the open circles and the number of replicated animals in each group was $n=3-4\left(6-8\right.$ mice). Results are displayed as the means $\pm \mathrm{S}$.E.M; ${ }^{*} \mathrm{p}<0.05,{ }^{*} \mathrm{p}<0.01, * * * \mathrm{p}<0.001$, compared to the non-smoking group (NS) group. 
A

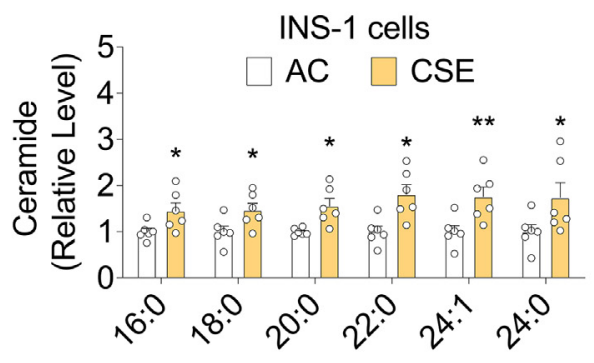

C

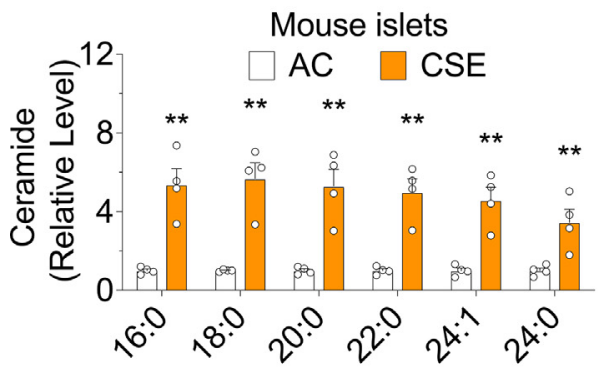

B

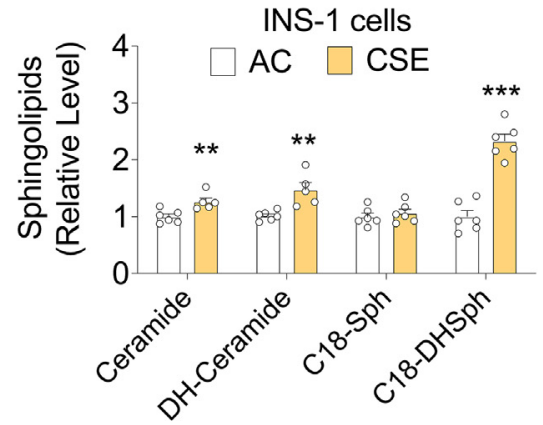

D

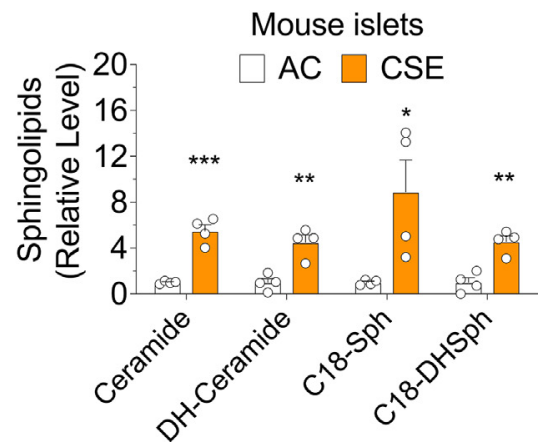

Figure 4: CSE treatment altered ceramide levels in INS-1 cells and isolated mouse islets. Cells and isolated mouse islets were incubated for $24 \mathrm{~h}$ with cigarette smoke extract (CSE) or air control (AC) extract that were prepared by bubbling ambient air or smoke at a rate of 1 cigarette/minute. (A and C) The concentrations of six different ceramides species were determined by LC-MS/MS. (B and D) Summary of LC-MS/MS results for total ceramide, dihydro (DH)-ceramide, C (18:0)-spingosince, and C (18:0) dihydro (DH)-sphingosine. The replicates of cell samples and islets samples are indicated by open circles. For cells, $n=5-6$. For islets, each sample was prepared from a total of 200 islets pooled from two mice, with a total of eight individual mice per group. Results are displayed as the means $\pm \mathrm{S}$.E.M; $* \mathrm{p}<0.05, * * \mathrm{p}<0.01$, $* * * \mathrm{p}<0.001$, compared to AC group.

A

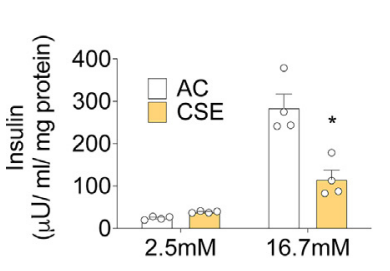

E

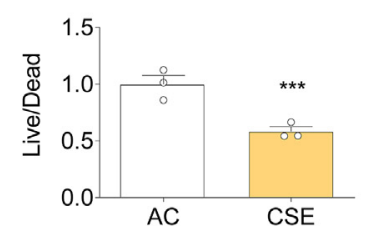

B

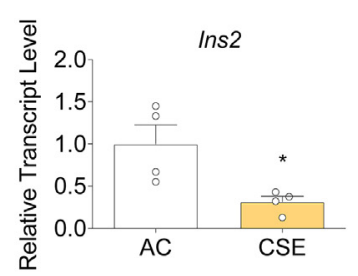

F

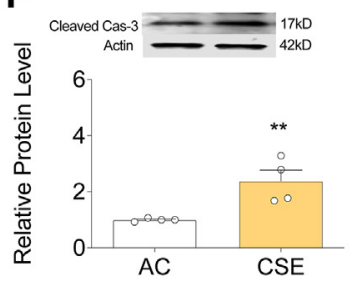

C

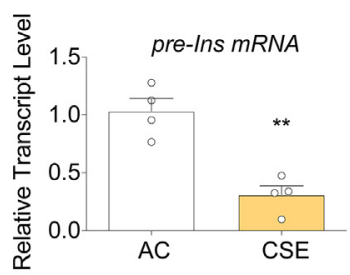

G

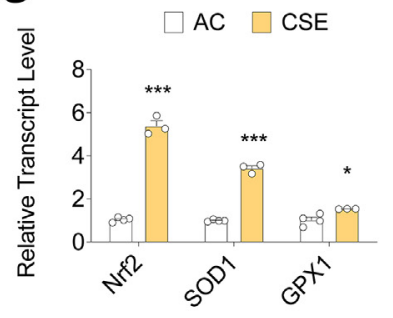

D

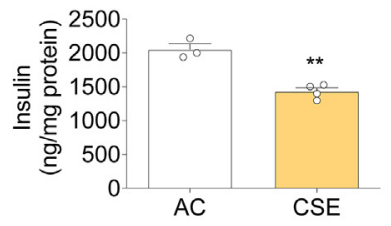

H

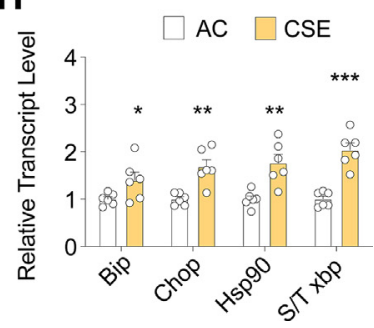

Figure 5: Exposure to CSE reduced insulin secretion and increased activation of $\boldsymbol{\beta}$-cell ER stress and oxidative stress. Cells were incubated for $24 \mathrm{~h}$ with cigarette smoke extract (CSE) or air control (AC) extracts as in Figure 4. (A) Glucose-stimulated insulin secretion into the supernatant was measured by ELISA and results were normalized to cellular protein levels. (B-C) RNA was isolated from treated INS-1 cells and insulin transcript levels were determined by qRT-PCR. (D) Cellular insulin levels were determined by ELISA with normalization of values to total protein levels. (E) Cell viability was determined by live/dead assay, and results are presented as the ratio of live to dead cells. (F) Immunoblotting was performed using caspase-3 and actin antibodies in control and CSE treated cells. Results were normalized with actin expression levels. (G) Cells were incubated for $6 \mathrm{~h}$ with CSE or AC extracts and gene expression of the oxidative stress markers Nrf2, Sod1 and Gpx1 were determined by qRT-PCR. Results were normalized with Actb expression levels. (H) Cells were incubated for $24 \mathrm{~h}$ with CSE or AC extracts. Expression of the ER stress marker genes, Bip, Chop, Hsp90, and spliced Xbp-1 ratio were analyzed as described in (G). The number of replicate samples for each analysis is indicated by the open circles; $n=3-6$. Results are displayed as the means $\pm \mathrm{S}$.E.M; $* \mathrm{p}<0.05, * * p<0.01, * * * p<0.001$ compared to the AC group. 
following CSE exposure, while immunoblot analysis revealed a significant increase in cleaved caspase- 3 expression in CSE-exposed $\beta$-cells (Figure 5E-F). Taken together, these results suggest that CSE exposure is able to directly induce ceramide accumulation in islets and $\beta$ cells, which was linked with reduced insulin secretion, impaired $\beta$-cell survival, and $\beta$-cell ER and oxidative stress.

\subsection{Antioxidant treatment prevented CSE-induced loss of $\beta$-cell function and viability}

To test whether approaches aimed at inhibiting ceramide synthesis might be able to prevent CSE-induced effects on $\beta$-cell viability, we tested the effect of multiple chemical ceramide synthesis inhibitors in CSE-treated INS-1 cells. We found no significant improvement in $\beta$-cell viability with either $4 \mu \mathrm{M}$ Fumonisin B1, $5 \mu \mathrm{M}$ GW4869, or $25 \mu \mathrm{M}$ Imipramine (Supplemental Figs. S1A-C). Consistent with this finding, mRNA expression of enzymes involved in ceramide synthesis pathways, including serine palmitoyltransferase 1 (SPT1), sphingomyelin phosphodiesterase 1 (SMPD1) and 2 (SMPD2) were unchanged in CSE-exposed INS1 cells (Supplemental Fig. S2) and significantly reduced in mouse islets (Supplemental Fig. S3A). In addition, immunoblot analysis revealed downregulation of SPT1 protein by CSE in mouse islets (Supplemental Fig. S3C). Interestingly, we observed reduced expression of amidohydrolase 1 (ASAH1) and sphingosinekinase 2 (SPHK2) in CSE-treated islets, suggesting the possibility of decreased catabolism/utilization of ceramides by CS (Supplemental Fig. S3B).

Next, we tested whether the reversal of either oxidative or ER stress could prevent CSE-induced $\beta$-cell dysfunction in experiments that utilized the antioxidant n-acetylcysteine (NAC: $5 \mathrm{mM}$ ) or the chemical chaperone tauroursodeoxycholic acid (TUDCA: $100 \mu \mathrm{M}$ ). The antioxidant effect of NAC was confirmed by its inhibitory effect on CSEinduced upregulation of Nrf2, a master transcriptional regulator of the cellular antioxidant response (Figure 6A). As expected, TUDCA prevented CSE-induced upregulation of ER stress markers without significantly inhibiting CS-induced upregulation of oxidative stress markers (Fig. 6B). Interestingly, ER stress was suppressed not only by TUDCA but also by NAC treatment, suggesting that CSE-induced ER stress may be linked to the induction of oxidative stress.

Treatment with NAC, but not with TUDCA, attenuated the effects of CSE on GSIS in INS-1 cells, suggesting a dominant role for oxidative stress in CSE-induced $\beta$-cell dysfunction (Fig. 6C). To further characterize the impact of NAC on phasic insulin secretion in CSE-treated mouse islets, perifusion experiments were performed. Here, CSE-treatment led to a marked reduction in first phase insulin release, while insulin secretion was significantly restored upon NAC treatment (Figure 6D-F). Similar to effects observed on insulin secretion, NAC treatment inhibited CSEinduced changes in $\beta$-cell viability as measured by live/dead assays (Fig. 6G). Moreover, NAC but not TUDCA reduced caspase-3 cleavage (Figure 6H-l).

Finally, considering the critical role that prohormone convertases play in proinsulin processing, we measured expression levels of PC1/3 in our in vitro model. Our results showed robust $(21 \%)$ down-regulation of the active form [30] (66 kD) of PC1/3 by CSE. In addition, NAC, but not TUDCA treatment, was able to restore PC1/3 expression in CSE-treated INS-1 cells (Fig.6J).

\subsection{Antioxidant treatment prevented the effects of CSE on sphingolipid accumulation in isolated mouse islets and restored mitochondrial respiratory function in CSE-treated INS-1 cells} Since our data suggested that antioxidant treatment, rather than selective prevention of ER stress, was necessary to mitigate the effects of
CSE on $\beta$-cell function, we next tested whether NAC also impacted CSE-induced changes in islet ceramide levels. Isolated mouse islets co-treated with NAC ( $5 \mathrm{mM}, 24 \mathrm{~h})$ and CSE showed a $>55 \%$ reduction in ceramide levels (Figure $7 \mathrm{~A}-\mathrm{B}$ ), with changes observed across all ceramide species $(P<0.05)$. Notably, the increase of the proapoptotic ceramide metabolite, hydroxy-ceramide [31] induced by CSE was markedly decreased by NAC (Fig. 7B). These data indicated that more than half of the excessive sphingolipid accumulation induced by CSE was oxidative stress-dependent.

To test whether alterations in mitochondria function contributed to the CSE-induced dysfunction of $\beta$-cells as previously described [32], we conducted analysis of mitochondria respiration using a Seahorse Extracellular Flux Analyzer. Oxygen Consumption Rates (OCR) were measured under basal conditions followed by the sequential addition of oligomycin $(2.0 \mu \mathrm{M})$, FCCP $(3.0 \mu \mathrm{M})$, rotenone/antimycin $(1.0 \mu \mathrm{M})$, which resulted in significant alteration of OCR (Figure 7C-D). CSE treatment significantly reduced the basal respiration (reduced by $68.0 \%, \mathrm{p}<0.0001$ ), maximal respiration (reduced by $64 \%$, $\mathrm{p}<0.0001$ ), proton leak (reduced by $65 \%, \mathrm{p}<0.0001$ ), and ATP production (reduced by $66 \%, \mathrm{p}<0.0001$ ), respectively (Fig. 7E). Notably, all of the changes in mitochondrial function induced by CSE were significantly reversed by antioxidant NAC treatment (Fig. 7E).

\subsection{CS down-regulated CyclinD2 and impaired cell proliferation in pancreatic islets}

To further understand how CS exposure reduced $\beta$-cell mass and proliferation, we interrogated cell cycle status in INS-1 cells after $24 \mathrm{~h}$ exposure to CSE. CSE reduced cell proliferation, which was characterized by an increased percentage of cells in the G0/G1 phase $(39.2 \%$ vs. $47.7 \% ; p<0.05)$ and a decreased percentage of cells in the G2/M phase $(45.3 \%$ vs. $37.4 \% ; p<0.05)$ (Figure $8 A)$. qRT-PCR analysis of a broad panel of cell cycle regulators revealed decreased cyclin D2 mRNA levels, while cyclin D1, and E1 mRNA levels were increased in CSE-treated cells (Fig.8B). Immunoblot analysis in INS-1 cells treated with CSE for $24 \mathrm{~h}$ showed a significant decrease in cyclin D2 protein expression (Fig.8C). Consistent with this result, CSE reduced cyclin D2 mRNA levels in isolated mouse islets (Fig.8D). To determine the relevance of these findings in our in vivo smoking model, immunostaining of cyclin D2 was performed in pancreatic sections collected from CS and NS-exposed mice at the 22-week timepoint. CS-exposed mice exhibited significant reductions in cyclin D2 expression within islets, supporting the notion that $\beta$-cell proliferation was reduced via the loss of this critical cell cycle regulator (Fig. 8E).

Finally, we tested a role for oxidative stress in cell-cycle regulation in our CSE-model. Treatment with NAC significantly attenuated the changes in cyclin D2 expression induced by CSE exposure (Figure 8FG), suggesting an important role for oxidative stress in cell cycle regulation. Using the same treatment conditions, we determined expression levels of cyclin-dependent kinase inhibitor p21, which is a known negative regulator of cyclin D2 [33]. Realtime qPCR analysis revealed a significant increase in $p 21$ expression in response to CSE treatment, which was prevented by NAC (Fig. 8H). Together, these results suggested that $\beta$-cell proliferation was reduced due to oxidative stress via the upregulation of $p 21$ coupled with a reduction in cyclin D2 (Fig.8I).

\section{DISCUSSION}

Despite an abundance of epidemiological data that links tobacco smoking with an increased risk of diabetes, little is known regarding the mechanisms underlying these associations. We aimed to address 
A
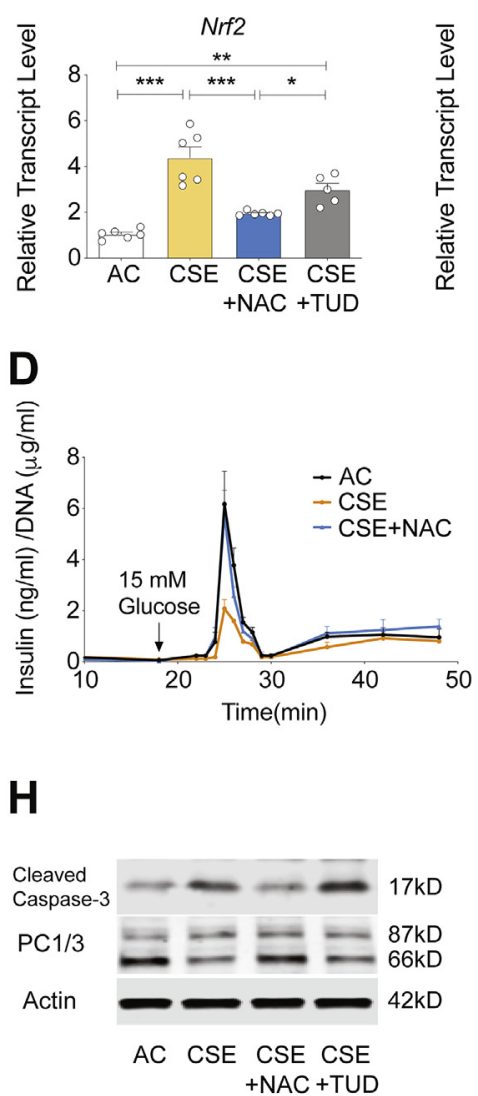

B

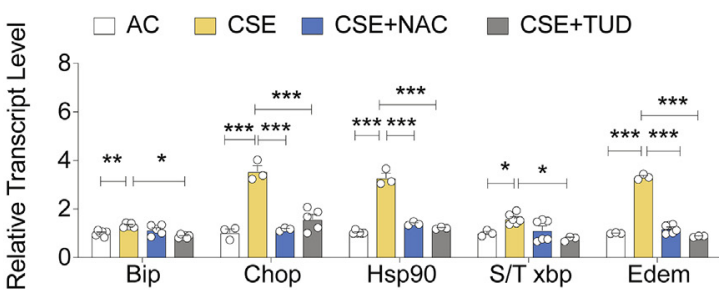

E

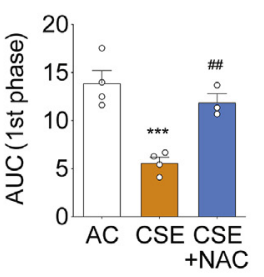

F

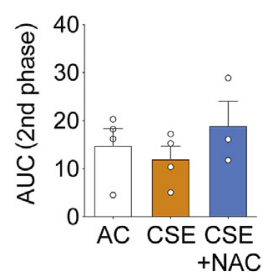

C

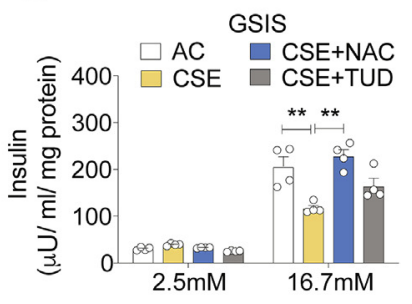

G

I

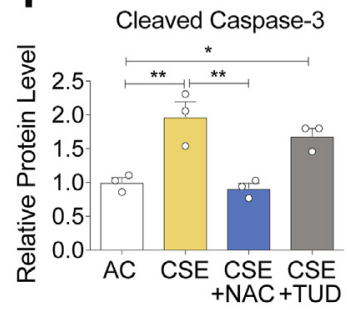

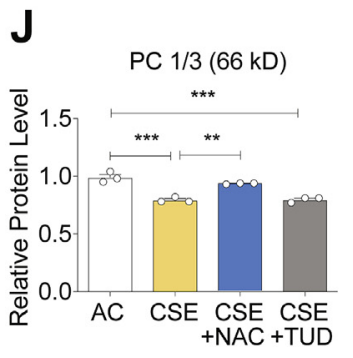

Figure 6: Antioxidant treatment prevented CSE-induced loss of $\beta$-cell function and viability. INS-1 cells were co-incubated with $\mathrm{N}$-acetylcysteine (NAC: $5 \mathrm{mM}$ ) or the chemical chaperone TUDCA (TUD: $100 \mu \mathrm{M}$ ) and cigarette smoke extract (CSE) for $24 \mathrm{~h}$ prior to assessment of indices of $\beta$-cell function. (A-B) RNA was isolated from treated INS-1 cells and gene expression of the oxidative stress marker Nrf2 and ER stress markers, Bip, Chop, Hsp90, and spliced Xbp-1 ratios were determined by qRT-PCR. (C) Glucosestimulated insulin secretion into the supernatant was measured by ELISA, and results were normalized to cellular protein levels. (D-F) Mouse islets were treated with CSE for $24 \mathrm{~h}$ and loaded into perifusion chambers and then perfused with Krebs buffer containing $2.8 \mathrm{mmol} / \mathrm{L}$ glucose for $20 \mathrm{~min}$, followed by $16.7 \mathrm{mmo} / \mathrm{L}$ glucose for $40 \mathrm{~min}$ at a rate of $120 \mu \mathrm{L} / \mathrm{min}$. Secreted insulin was measured using ELISA, and the results were normalized to total DNA content. (G-I) Total protein was isolated from treated cells and immunoblotting was performed using antibodies recognizing caspase-3, Cyclin D2, proprotein convertase and actin. Results were normalized to actin levels. (J) Cell viability was determined by a live/dead assay, and results expressed as the ratio of live to dead cells. The numbers of replicates for each measurement are indicated by the open circles, $\mathrm{n}=3-4$. Results are displayed as the means \pm S.E.M; ${ }^{*} \mathrm{p}<0.05,{ }^{* *} \mathrm{p}<0.01, * * * \mathrm{p}<0.001$ for indicated comparisons.

this knowledge gap by using a murine in vivo model of chronic CS exposure combined with HFD. Data from our in vivo model was complemented by analysis of an in vitro model of acute CS exposure using INS-1 cells and isolated islets exposed to soluble components of $\mathrm{CS}$. To the best of our knowledge, this is the first study to investigate the mechanisms by which CS impacts $\beta$-cell health and function. Notably, we included in our experimental design assessments of the direct effects of CS measured during a relatively chronic period of CS exposure, as well as the effects of CS that were sustained following an equal period of CS cessation. Extrapolating lifespans of mice to humans, these timeframes have been linked with metabolic dysfunction and diabetes risk. In persons with and without diabetes, cigarette smoking is independently associated with higher hemoglobin A1c $(\mathrm{HbA1C})$ concentrations [34], and diabetes risk increases in a dose-dependent manner with the number of cigarettes smoked per day [35]. Interestingly, the risk of diabetes is also heightened in those who have recently quit smoking, and this risk has been found to correlate with weight gain following cessation. Therefore the mouse model used in our studies is highly relevant to exploring the mechanisms of human metabolic dysregulation that links CS, obesity, and hyperglycemia.

As previously reported in CS-exposed mice fed regular chow [18], mice in our study displayed reduced total body weight gain during CS exposure, even when fed an HFD. This observation is consistent with the known effects of CS to suppress appetite and increase energy expenditure [20]. Glucose and insulin tolerance largely followed weight patterns. During the active smoking period, CS-exposed mice were more glucose tolerant and more insulin sensitive compared to HFD-fed air control mice. In addition, GTT and ITTs were not different between the smoking and non-smoking groups at the end of the 22-week observation period. However, mice exposed to CS, who then underwent smoking cessation, exhibited an accelerated body weight gain with an associated rapid worsening of their glucose and insulin tolerance. Interestingly, despite equivalent body weights between CS exposed and control mice at treatment end, CS-exposed mice had reduced $\beta$-cell mass and proliferation, reduced serum insulin levels, and increased proinsulin/insulin ratios, suggesting that the chronic CS exposure reduced the capacity for $\beta$-cell adaptation in the setting of 
A

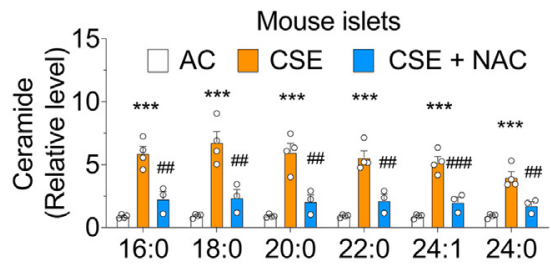

C

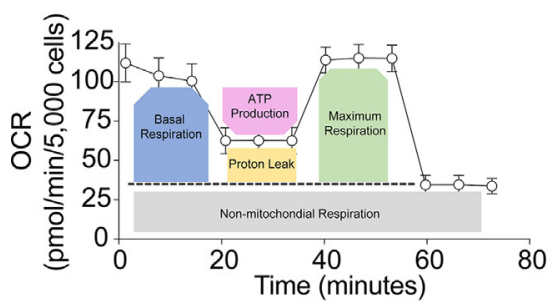

B

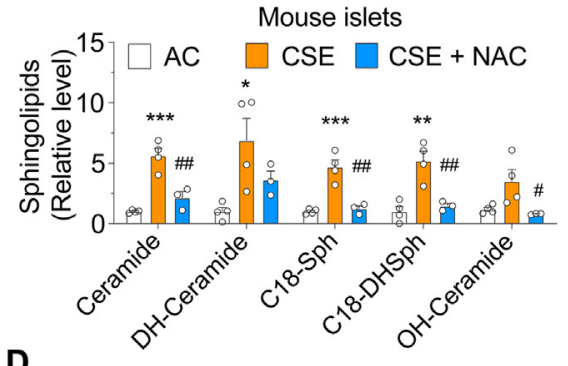

E

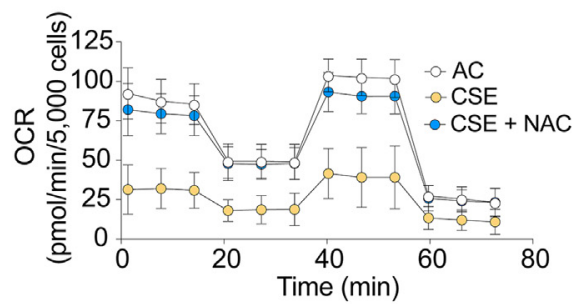

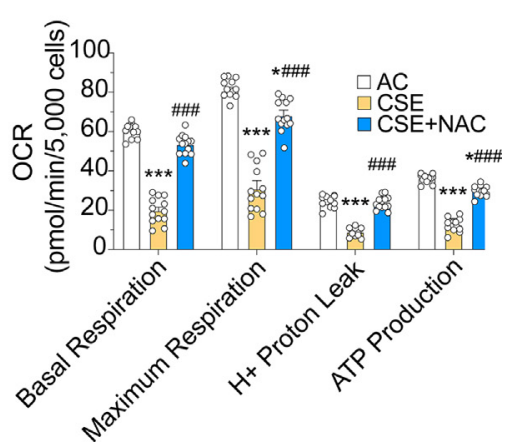

Figure 7: Antioxidant treatment prevented the effect of CSE on lipid accumulation in isolated mouse islets and restored mitochondrial respiration in INS-1 cells treated with CSE. Mouse islets were co-incubated with $\mathrm{N}$-acetylcysteine (NAC: $5 \mathrm{mM}$ ) and cigarette smoke extract (CSE) for $24 \mathrm{~h}$ prior to analysis of lipid levels. (A-B) Summary of LC-MS/MS results for total ceramide, dihydro (DH)-ceramide C (18:0)-spingosine, C (18:0) dihydro (DH)-sphingosine measurement, and hydroxy-ceramide. Each sample was prepared from total 200 islets pooled from two mice, total 6-8 individual mice per group. (C-E) INS1 cells were co-incubated with N-acetylcysteine (NAC: 5 mM) and cigarette smoke extract (CSE) for $20 \mathrm{~h}$ prior to analysis. Mitochondrial respiration was measured using the Seahorse Extracellular Flux Analyzer XFe96 and Cell Mito Stress Test Kit. Schematic (C) and oxygen consumption rate (OCR) (D) assessed by extracellular flux analysis. OCR was measured under basal conditions followed by the sequential addition of oligomycin $(2.0 \mu \mathrm{M})$, FCCP $(3.0 \mu \mathrm{M})$, rotenone/antimycin $(1.0 \mu \mathrm{M})$. Each data point represents an OCR measurement. (E) Individual parameters for basal respiration, maximal respiration, proton leak, and ATP production were normalized to cell count. The numbers of replicates for each experiment are indicated by the open circles, $\mathrm{n}=3-4$. Results are displayed as the means \pm S.E.M; ${ }^{*} \mathrm{p}<0.05,{ }^{* *} \mathrm{p}<0.01,{ }^{* * *} \mathrm{p}<0.001$ compared to AC, ${ }^{\#} \mathrm{p}<0.05,{ }^{\# \#} \mathrm{p}<0.01,{ }^{\# \# \#} \mathrm{p}<0.001$ compared to CSE group.

continued HFD exposure. Notably, these mice were also found to have increased ceramide levels within their islets.

The lung, which is directly exposed via inhalation to the toxic effects of tobacco smoking, exhibits a multitude of cellular responses to chronic CS exposure that include oxidative stress, inflammation, lung cell injury that results in cell death and tissue remodeling, as well as neoplasia [36]. In particular, in pulmonary emphysema, which is primarily caused by chronic CS, excessive ceramide production has been a major contributor to the apoptotic loss of lung endothelial cells that participate in gas exchange [19]. CS exposure in mice increased ceramide production in other organs, including cardiomyocytes, leading to disrupted cardiomyocyte mitochondrial function [20], and the skeletal muscle [37]. In addition to a local production of ceramides in various tissues, typically as a result of CS-induced oxidative stress [38] or mitochondrial dysfunction [39], systemic ceramides are increased during CS and can cause tissue damage. There are numerous studies of how CS affects serum lipid profiles in general - most focusing on cholesterol and associated lipoproteins, and how these are only partially reversible upon smoking cessation [40]. Regarding ceramides in particular, CS alone can result in the release of ceramide-rich endothelial exosomes and microparticles into the systemic circulation [41]. Profiling of metabolites in the serum of smokers and exsmokers indicated an accelerated production of ceramide in those affected with chronic lung disease [42]. Furthermore, a study of former smokers that also evaluated the impact of obesity and high-fat western diet on plasma lipids, suggested that these were associated with elevated levels of serum ceramides [43]. Thus islets could be indirectly affected by CS-induced increases in circulating ceramides or by other soluble components of CS that cross the alveolar-capillary lung barrier and are distributed to tissues via the circulation [20,44]. Alternatively, they could be injured by mediators released by other CS-activated cells in a paracrine manner [28,29]. A third alternative is that CS-induced changes in ceramide content arise via effects on multiple sphingolipid metabolic pathways that participate in its synthesis, such as the de novo pathway, sphingomyelin hydrolysis, activation of recycling pathways, or inhibition of its catabolism/utilization towards smaller sphingolipids and the synthesis of complex sphingolipids.

To determine the direct effects of CS on $\beta$-cells and isolated mouse islets, we exposed them ex vivo to CSE and found that CSE markedly decreased $\beta$-cell proliferation, viability, insulin biosynthesis, maturation, and secretion. In parallel, ceramide levels were increased within both CS-exposed islets and INS-1 $\beta$-cells. We next investigated whether inhibition of ceramide synthesis could alter the effects of CS. Results from these experiments were largely negative, suggesting that upregulation of ceramide synthesis is not the main pathway responsible for increased ceramide accumulation in response to CSE exposure. In support of this, gene expression of key enzymes for ceramide synthesis were decreased by CSE treatment in islets. Future studies of sphingolipid metabolic flux will be needed to clarify fully the state of ceramide metabolism in $\beta$-cells during all phases of smoking exposure and cessation.

Nevertheless, multiple reports, recently reviewed by Boslem et al. indicate that the accumulation of ceramide and other sphingolipids can have a major impact on pancreatic $\beta$-cell function in both T1D and T2D 
A

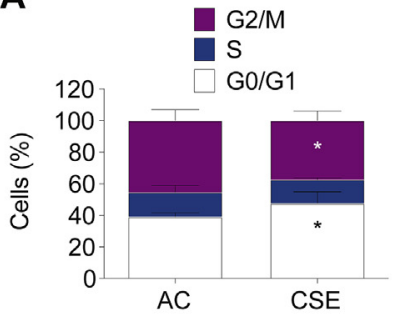

D

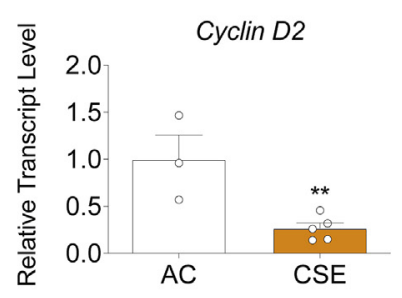

G

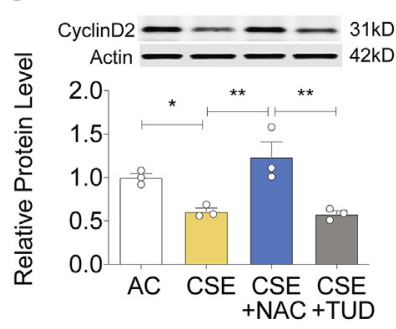

B

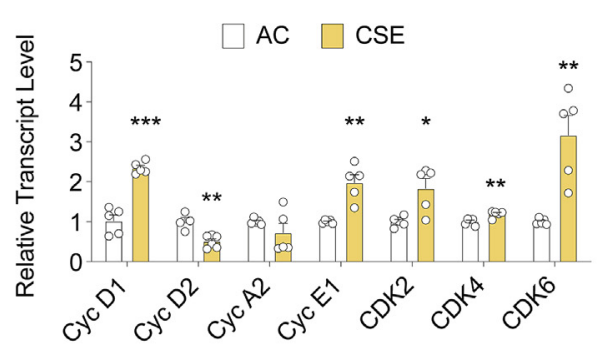

E

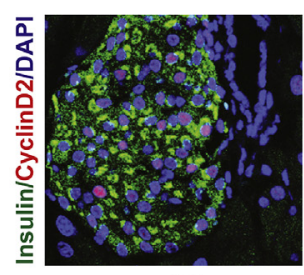

NS

H

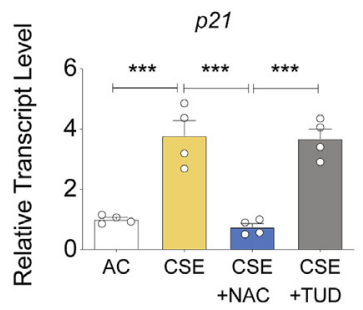

C CyclinD2 $-31 \mathrm{kD}$
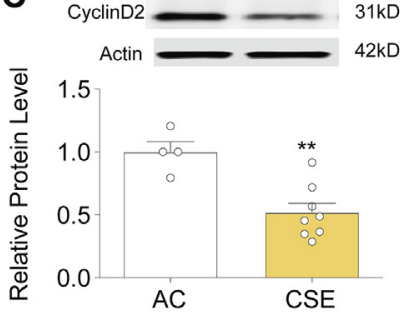

$\mathbf{F}$
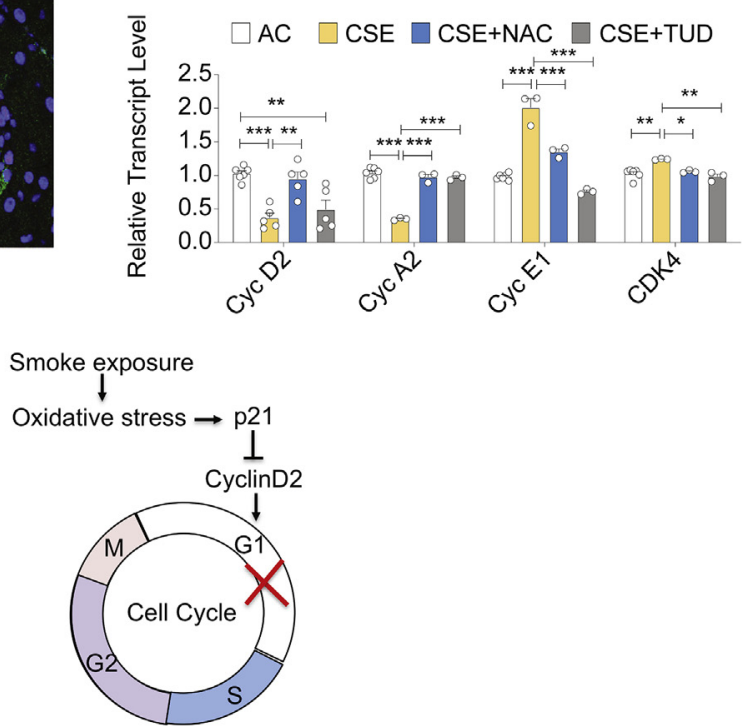

Figure 8: CS impaired $\beta$-cell proliferation through cyclin D2 loss. (A) INS-1 cells were incubated with AC or CSE for $24 \mathrm{~h}$ and stained with propidium iodide (PI), and cell cycle analysis was performed using flow cytometry. (B) Total RNA was isolated from treated INS-1 cells, and gene expression of a panel of cyclin genes was performed (Cyclin D1 (Ccnd1), D2 (Ccnd2), D3 (Ccnd3), A2 (Ccna2), E1 (Ccne1), G1 (Ccng1), Cdk2, Cdk4, Cdk6 were determined by qRT-PCR. (C) Total protein was isolated from treated cells and immunoblotting was performed using antibodies against Cyclin D2 and actin. Results were normalized to actin levels. (D) Mouse islets were treated with $5 \%$ CSE for $24 \mathrm{~h}$ and qRTPCR of CyclinD2 was performed. (E) Immunostaining images of paraffin sections of pancreata from C57BL/6 J mouse treated with the combination of CS and HFD for 22 weeks. (F-H) INS-1 cells were co-incubated with N-acetylcysteine (NAC: $5 \mathrm{mM}$ ) or the chemical chaperone TUDCA (TUD: $100 \mu \mathrm{M}$ ) and CSE for $24 \mathrm{~h}$ prior to assessment of gene or protein expression. RNA was isolated from treated INS-1 cells and gene expression of potent cyclin-dependent kinase inhibitor p21(Cdkn1a) and cyclin genes (Ccnd2, Ccna2, Ccne1, Cdk4) were determined by qRT-PCR ( $\mathrm{F}$ and $\mathrm{H})$. Cyclin D2 protein level was determined by immunoblotting $(\mathrm{G})$; (l) Hypothesized pathway for oxidative stress-dependent cell cycle arrest in $\beta$-cell. The numbers of replicates for each experiment are indicated by the open circles. Results are displayed as the means $\pm \mathrm{S} . \mathrm{E} . \mathrm{M}$; ${ }^{*} \mathrm{p}<0.05,{ }^{*} \mathrm{p}<0.01,{ }^{*} * \mathrm{*}<<0.001$ compared to AC treatment.

[45]. Sphingolipid metabolites, such as ceramide, sphingosine-1phosphate, and sphingomyelin, have been linked with activation of oxidative and ER stress [45], $\beta$-cell apoptosis [46], disruption of vesicle-trafficking [47], and inhibition of insulin gene expression [48]. Concurrently, many of these pathways are also reported to be involved in smoking related toxicity in other cell types $[18,19]$. Indeed, gene expression of both oxidative and ER stress markers were upregulated in our in vitro model of smoke exposure, indicating a critical role for these stress pathways in smoking related $\beta$-cell failure. Although prior studies suggested the importance of ER stress in ceramide-induced apoptosis and impaired $\beta$-cell function $[45,49]$, our results demonstrated that rescue of ER stress by the chemical chaperone TUDCA did not mitigate the overall effects of CSE. In contrast, antioxidant treatment with NAC markedly reduced CSE-induced apoptosis, normalized expression of PC1/3 and Cyclin D2, and restored first phase insulin secretion. Interestingly, NAC reduced CSE-induced ceramide accumulation as well as ER stress, suggesting that oxidative stress could play a determining role in ceramide signaling and the regulation of $\beta$ - cell apoptosis and dysfunction in response to CSE. A similar effect of NAC on CSE-induced cell death was reported previously in lung endothelial and epithelial cells [18,50]; however, our study is the first to suggest that NAC may have beneficial effects on the $\beta$-cell in smoking models. Tobacco smoke contains over 4000 noxious chemicals as well as free radicals and reactive oxygen species (ROS), with many reported to show potential for biological oxidative damage due to smoking $[51,52]$. In addition, it has also been reported that ceramide accumulation can further increase oxidative stress [38], via several mechanisms, including direct effects on the mitochondrial membrane [53]. Thus, oxidative damage could be induced by free radicals and ROS, which can be amplified when combined with ceramide accumulation. Indeed, our data clearly demonstrated that CSE treatment led to reduced mitochondrial function, including decreased respiration, proton leak, and ATP production in INS-1 cells. These effects were reversed by antioxidant treatment, suggesting an important mechanistic involvement of the mitochondria in CS-induced $\beta$-cell toxicity. Although further experimentation is needed, our data suggest a 
potential mutual, self-amplified interaction of ceramide and ROS in CS induced- $\beta$-cell dysfunction.

The role of individual ceramide species in disease pathogenesis in general and in diabetes is far from being fully elucidated. However, our data is consistent with other reports in models of diabetes, where ceramides with palmitoyl, behenic, and unsaturated lignoceroyl fatty acids have been reported to be elevated in islets of streptozotocintreated rats [54]. Furthermore, in a study of mice fed an HFD, mice deficient in the enzyme that metabolized sphingosine to S1P (SPhK1) were more likely to develop diabetes associated with enhanced $\beta$-cell apoptosis, further augmented by palmitic fatty acids, whereas S1P had a pro-survival effect [55]. Although we did not measure S1P levels, the further elevations in sphingosine and palmitoyl ceramide in CSexposed mice and islet cells are consistent with these results.

There are limitations to our study that should be considered. First, our primary focus was to elucidate pathways associated with smoking induced pancreatic $\beta$-cell dysfunction. Human physiological data has shown that smoking also impacts insulin sensitivity. Indeed, we observed evidence of worsened insulin resistance after smoking cessation in our in vivo studies, but we did not explore mechanisms associated with this finding. Our intent was to create an in vivo model that fully recapitulated human responses to smoking. However, we did not observe worsened glucose tolerance during the smoke exposure period, likely due to the complexity of nicotine signaling on appetite and energy expenditure. We overcame this limitation by coupling our in vivo studies with an in vitro model of CSE-treatment in $\beta$-cells and islets. Our study utilized male mice only, so we cannot extrapolate these results to female animals.

Notwithstanding these limitations, our data identify several critical mechanisms through which smoking impacts pancreatic $\beta$-cell function and survival. We found that smoking led to increased ceramide content that was correlated with the activation of oxidative and endoplasmic reticulum stress. At a mechanistic level, these changes were associated with reduced insulin production, impaired insulin processing, and reduced insulin secretion as well as reduced $\beta$-cell viability and proliferation. Taken together, these data provide novel insights into the mechanisms whereby cigarette smoking increases the risk of T2D during both the smoking period and during the immediate cessation period.

\section{CONCLUSION}

In summary, we conclude that CS exposure elevates the risk of impaired glucose homeostasis through $\beta$-cell dysfunction caused by oxidative stress and ceramide accumulation.

\section{AUTHOR CONTRIBUTIONS}

X.T. and Z.C. design of the study, data analysis and interpretation, collection and assembly of data, and manuscript draft writing. C.L., R.N.B., S.K., J.M., P.S., S.A.W., and M.A.R. participated in data collection and critical revision of the manuscript. I.P. contributed to data analysis, provided critical reagents, and provided critical revision of the manuscript. C.E.-M.: directed funding acquisition, study conception and design, directed manuscript writing, and gave final approval of the manuscript. T.K. directed funding acquisition, conception and design of the study, data analysis and interpretation, collection and assembly of data, and manuscript writing/editing. T.K., I.P., and C.E.-M. are the guarantors of this work, had full access to all of the study data, and take responsibility for the integrity and accuracy of the data.

\section{FUNDING}

This work was supported by Showalter young investigator award from the Indiana University School of Medicine (to T.K.), National Institute of Diabetes and Digestive and Kidney Diseases grants R01-DK-093954 and DK-104166 (to C.E.-M.), U.S. Department of Veterans Affairs Merit Award I01BX001733 (to C.E.-M.), and gifts from the Sigma Beta Sorority, the Ball Brothers Foundation, and the George and Frances Ball Foundation (to C.E.-M.). X.T. was supported by the Diabetes and Obesity DeVault Fellowship at the Indiana University School of Medicine. R.N.B. was supported by NIH NIAID Training Grant (T32 Al060519) and a JDRF Postdoctoral Research Award (3-PDF-2017385-A-N). R01HL077328 (to I. P.). The funders had no role in study design, data collection and analysis, decision to publish, or preparation of the manuscript. The authors acknowledge the support of the Islet and Physiology and Translation Cores of the Indiana Diabetes Research Center (P30-DK-097512).

\section{ACKNOWLEDGEMENT}

The authors would like to thank Dr. Donalyn Scheuner (Indiana Bioscience Research Institute) for her helpful advice and discussions. The authors would also like to thank Dr. Evgeny Berdyshev (National Jewish Health) for his assistance with ceramide analysis. We thank Dr. Kathleen Heidler, and Jacob Saliba (Indiana University), for their technical support for in vivo smoke exposure experiments. We also thank Kara Orr and Karishma Randhave (Indiana University) for their technical assistance.

\section{CONFLICT OF INTEREST}

No potential conflicts of interest relevant to this article were reported.

\section{APPENDIX A. SUPPLEMENTARY DATA}

Supplementary data to this article can be found online at https://doi.org/10.1016/j. molmet.2020.100975.

\section{REFERENCES}

[1] Federation, I.D., 2015. IDF diabetes atlas, 7th ed. Belgium: Brussels.

[2] Spaulding, A.C., Eldridge, G.D., Chico, C.E., Morisseau, N., Drobeniuc, A., FilsAime, R., et al., 2018. Smoking in correctional settings worldwide: prevalence, bans, and interventions. Epidemiological Review, 82-95.

[3] Drope, J.S.N., Cahn, Z., Hamill, S., Islami, F., Liber, A., Nargis, N., et al., 2018. Tobacco atlas, 6thEdition. American Cancer Society and Vital Strategies.

[4] Wang, Y., Ji, J., Liu, Y.J., Deng, X., He, Q.Q., 2013. Passive smoking and risk of type 2 diabetes: a meta-analysis of prospective cohort studies. PloS One 8(7):e69915.

[5] Pan, A., Wang, Y., Talaei, M., Hu, F.B., Wu, T., 2015. Relation of active, passive, and quitting smoking with incident type 2 diabetes: a systematic review and meta-analysis. Lancet Diabetes Endocrinol 3(12):958-967.

[6] Willi, C., Bodenmann, P., Ghali, W.A., Faris, P.D., Cornuz, J., 2007. Active smoking and the risk of type 2 diabetes: a systematic review and metaanalysis. Journal of the American Medical Association 298(22):2654-2664.

[7] Athyros, V.G., Katsiki, N., Doumas, M., Karagiannis, A., Mikhailidis, D.P., 2013. Effect of tobacco smoking and smoking cessation on plasma lipoproteins and associated major cardiovascular risk factors: a narrative review. Current Medical Research and Opinion 29(10):1263-1274.

[8] Godsland, I.F., Walton, C., 1992. Insulin resistance and cigarette smoking. Lancet 340(8819):607. 
[9] Fagard, R.H., Nilsson, P.M., 2009. Smoking and diabetes-the double health hazard! Prim Care Diabetes 3(4):205-209.

[10] Arnson, Y., Shoenfeld, Y., Amital, H., 2010. Effects of tobacco smoke on immunity, inflammation and autoimmunity. Journal of Autoimmunity 34(3): J258-J265.

[11] Wannamethee, S.G., Shaper, A.G., Perry, I.J., 2001. Smoking as a modifiable risk factor for type 2 diabetes in middle-aged men. Diabetes Care 24(9): 1590-1595.

[12] Yeh, H.C., Duncan, B.B., Schmidt, M.l., Wang, N.Y., Brancati, F.L., 2010. Smoking, smoking cessation, and risk for type 2 diabetes mellitus: a cohort study. Annals of Internal Medicine 152(1):10-17.

[13] Hu, Y., Zong, G., Liu, G., Wang, M., Rosner, B., Pan, A., et al., 2018. Smoking cessation, weight change, type 2 diabetes, and mortality. New England Journal of Medicine 379(7):623-632.

[14] Su, Y., Han, W., Giraldo, C., De Li, Y., Block, E.R., 1998. Effect of cigarette smoke extract on nitric oxide synthase in pulmonary artery endothelial cells. American Journal of Respiratory Cell and Molecular Biology 19(5):819-825.

[15] Csordas, A., Kreutmayer, S., Ploner, C., Braun, P.R., Karlas, A., Backovic, A., et al., 2011. Cigarette smoke extract induces prolonged endoplasmic reticulum stress and autophagic cell death in human umbilical vein endothelial cells. Cardiovascular Research 92(1):141-148.

[16] Lemaitre, V., Dabo, A.J., D’Armiento, J., 2011. Cigarette smoke components induce matrix metalloproteinase- 1 in aortic endothelial cells through inhibition of mTOR signaling. Toxicological Sciences 123(2):542-549.

[17] Kunchithapautham, K., Atkinson, C., Rohrer, B., 2014. Smoke exposure causes endoplasmic reticulum stress and lipid accumulation in retinal pigment epithelium through oxidative stress and complement activation. Journal of Biological Chemistry 289(21):14534-14546.

[18] Schweitzer, K.S., Hatoum, H., Brown, M.B., Gupta, M., Justice, M.J., Beteck, B., etal., 2011. Mechanisms of lung endothelial barrier disruption induced by cigarette smoke: role of oxidative stress and ceramides. American Journal of Physiology Lung Cellular and Molecular Physiology 301(6):L836-L846.

[19] Petrache, I., Natarajan, V., Zhen, L., Medler, T.R., Richter, A.T., Cho, C., et al., 2005. Ceramide upregulation causes pulmonary cell apoptosis and emphysema-like disease in mice. Nature Medicine 11(5):491-498.

[20] Tippetts, T.S., Winden, D.R., Swensen, A.C., Nelson, M.B., Thatcher, M.O., Saito, R.R., et al., 2014. Cigarette smoke increases cardiomyocyte ceramide accumulation and inhibits mitochondrial respiration. BMC Cardiovascular Disorders 14:165.

[21] Teague, S.V., Pinkerton, K.E., Goldsmith, M., Gebremichael, A., Chang, S., Jenkins, R.A., et al., 2008. Sidestream cigarette smoke generation and exposure system for environmental tobacco smoke studies. Inhalation Toxicology 6(1):79-93.

[22] Tong, X., Kono, T., Anderson-Baucum, E.K., Yamamoto, W., Gilon, P., Lebeche, D., etal., 2016. SERCA2 deficiency impairs pancreatic beta-cell function in response to diet-induced obesity. Diabetes 65(10):3039-3052.

[23] Sims, E.K., Hatanaka, M., Morris, D.L., Tersey, S.A., Kono, T., Chaudry, Z.Z., et al., 2013. Divergent compensatory responses to high-fat diet between C57BL6/J and C57BLKS/J inbred mouse strains. American Journal of Physiology. Endocrinology and Metabolism 305(12):E1495-E1511.

[24] Jetton, T.L., Lausier, J., LaRock, K., Trotman, W.E., Larmie, B., Habibovic, A., et al., 2005. Mechanisms of compensatory beta-cell growth in insulin-resistant rats: roles of Akt kinase. Diabetes 54(8):2294-2304.

[25] Kono, T., Ahn, G., Moss, D.R., Gann, L., Zarain-Herzberg, A., Nishiki, Y., et al., 2012. PPAR-gamma activation restores pancreatic islet SERCA2 levels and prevents beta-cell dysfunction under conditions of hyperglycemic and cytokine stress. Molecular Endocrinology 26(2):257-271.

[26] Kono, T., Tong, X., Taleb, S., Bone, R.N., lida, H., Lee, C.C., et al., 2018. Impaired store-operated calcium entry and STIM1 loss lead to reduced insulin secretion and increased endoplasmic reticulum stress in the diabetic beta-cell. Diabetes 67(11):2293-2304.
[27] Wang, C.Y., Liao, J.K., 2012. A mouse model of diet-induced obesity and insulin resistance. Methods in Molecular Biology 821:421-433.

[28] Sliwinska-Mosson, M., Milnerowicz, H., Milnerowicz, S., Nowak, M., Rabczynski, J., 2012. Immunohistochemical localization of somatostatin and pancreatic polypeptide in smokers with chronic pancreatitis. Acta Histochemica 114(5):495-502.

[29] Caicedo, A., 2013. Paracrine and autocrine interactions in the human islet: more than meets the eye. Seminars in Cell \& Developmental Biology 24(1):11-21.

[30] Hoshino, A., Kowalska, D., Jean, F., Lazure, C., Lindberg, I., 2011. Modulation of PC1/3 activity by self-interaction and substrate binding. Endocrinology 152(4):1402-1411.

[31] Szulc, Z.M., Bai, A., Bielawski, J., Mayroo, N., Miller, D.E., Gracz, H., et al., 2010. Synthesis, NMR characterization and divergent biological actions of 2'hydroxy-ceramide/dihydroceramide stereoisomers in MCF7 cells. Bioorganic \& Medicinal Chemistry 18(21):7565-7579.

[32] Bhattacharjee, A., Prasad, S.K., Banerjee, O., Singh, S., Banerjee, A., Bose, A. et al., 2018. Targeting mitochondria with folic acid and vitamin B12 ameliorates nicotine mediated islet cell dysfunction. Environmental Toxicology 33(9): 988-1000.

[33] Kaneto, H., Kajimoto, Y., Fujitani, Y., Matsuoka, T., Sakamoto, K., Matsuhisa, M., et al., 1999. Oxidative stress induces p21 expression in pancreatic islet cells: possible implication in beta-cell dysfunction. Diabetologia 42(9):1093-1097.

[34] Choi, D.-W., Jeon, J., Lee, A.S., Han, K.-T., Park, E.-C., Jang, S.-I., 2018. Association between smoking behavior patterns and glycated hemoglobin levels in a general population. International Journal of Environmental Research and Public Health 15(10).

[35] Jee, S.H., Foong, A.W., Hur, N.W., Samet, J.M., 2010. Smoking and risk for diabetes incidence and mortality in Korean men and women. Diabetes Care 33(12):2567-2572.

[36] Tuder, R.M., Petrache, I., 2012. Pathogenesis of chronic obstructive pulmonary disease. Journal of Clinical Investigation 122(8):2749-2755.

[37] Thatcher, M.O., Tippetts, T.S., Nelson, M.B., Swensen, A.C., Winden, D.R. Hansen, M.E., et al., 2014. Ceramides mediate cigarette smoke-induced metabolic disruption in mice. American Journal of Physiology. Endocrinology and Metabolism 307(10):E919-E927.

[38] Petrache, I., Medler, T.R., Richter, A.T., Kamocki, K., Chukwueke, U., Zhen, L., et al., 2008. Superoxide dismutase protects against apoptosis and alveolar enlargement induced by ceramide. American Journal of Physiology - Lung Cellular and Molecular Physiology 295(1):L44-L53.

[39] Mizumura, K., Justice, M.J., Schweitzer, K.S., Krishnan, S., Bronova, I., Berdyshev, E.V., et al., 2018. Sphingolipid regulation of lung epithelial cell mitophagy and necroptosis during cigarette smoke exposure. The FASEB Journal 32(4):1880-1890.

[40] Maeda, K., Noguchi, Y., Fukui, T., 2003. The effects of cessation from cigarette smoking on the lipid and lipoprotein profiles: a meta-analysis. Preventive Medicine 37(4):283-290.

[41] Serban, K.A., Rezania, S., Petrusca, D.N., Poirier, C., Cao, D., Justice, M.J., et al., 2016. Structural and functional characterization of endothelial microparticles released by cigarette smoke. Scientific Reports 6:31596.

[42] Bowler, R.P., Jacobson, S., Cruickshank, C., Hughes, G.J., Siska, C., Ory, D.S., et al., 2015. Plasma sphingolipids associated with chronic obstructive pulmonary disease phenotypes. American Journal of Respiratory and Critical Care Medicine 191(3):275-284.

[43] Drazba, A.M., Holásková, I., Sahyoun, R.N., Ventura Marra, M., 2019. Associations of adiposity and diet quality with serum ceramides in middle-aged adults with cardiovascular risk factors. Journal of Clinical Medicine 8(4).

[44] Levy, M., Khan, E., Careaga, M., Goldkorn, T., 2009. Neutral sphingomyelinase 2 is activated by cigarette smoke to augment ceramide-induced apoptosis in lung cell death. American Journal of Physiology - Lung Cellular and Molecular Physiology 297(1):L125-L133. 
[45] Boslem, E., Meikle, P.J., Biden, T.J., 2012. Roles of ceramide and sphingolipids in pancreatic beta-cell function and dysfunction. Islets 4(3):177-187.

[46] Veluthakal, R., Palanivel, R., Zhao, Y., McDonald, P., Gruber, S., Kowluru, A., 2005. Ceramide induces mitochondrial abnormalities in insulin-secreting INS1 cells: potential mechanisms underlying ceramide-mediated metabolic dysfunction of the $\beta$ cell. Apoptosis 10(4):841-850.

[47] Gjoni, E., Brioschi, L., Cinque, A., Coant, N., Islam, M.N., Ng, C.K., et al., 2014. Glucolipotoxicity impairs ceramide flow from the endoplasmic reticulum to the Golgi apparatus in INS-1 beta-cells. PloS One 9(10):e110875.

[48] Kelpe, C.L., Moore, P.C., Parazzoli, S.D., Wicksteed, B., Rhodes, C.J., Poitout, V., 2003. Palmitate inhibition of insulin gene expression is mediated at the transcriptional level via ceramide synthesis. Journal of Biological Chemistry 278(32):30015-30021.

[49] Lei, X., Zhang, S., Emani, B., Barbour, S.E., Ramanadham, S., 2010. A link between endoplasmic reticulum stress-induced beta-cell apoptosis and the group VIA Ca2+-independent phospholipase A2 (iPLA2beta). Diabetes, Obesity and Metabolism 12(Suppl 2):93-98.

[50] Kosmider, B., Messier, E.M., Chu, H.W., Mason, R.J., 2011. Human alveolar epithelial cell injury induced by cigarette smoke. PloS One 6(12): e26059.
[51] Valavanidis, A., Vlachogianni, T., Fiotakis, K., 2009. Tobacco smoke: involvement of reactive oxygen species and stable free radicals in mechanisms of oxidative damage, carcinogenesis and synergistic effects with other respirable particles. International Journal of Environmental Research and Public Health 6(2):445-462.

[52] Isik, B., Ceylan, A., Isik, R., 2007. Oxidative stress in smokers and nonsmokers. Inhalation Toxicology 19(9):767-769.

[53] García-Ruiz, C., Colell, A., Marí, M., Morales, A., Fernández-Checa, J.C., 1997. Direct effect of ceramide on the mitochondrial electron transport chain leads to generation of reactive oxygen species: role OF mitochondrial glutathione. Journal of Biological Chemistry 272(17):11369-11377.

[54] Fox, T.E., Bewley, M.C., Unrath, K.A., Pedersen, M.M., Anderson, R.E., Jung, D.Y., et al., 2011. Circulating sphingolipid biomarkers in models of type 1 diabetes. The Journal of Lipid Research 52(3):509-517.

[55] Qi, Y., Chen, J., Lay, A., Don, A., Vadas, M., Xia, P., 2013. Loss of sphingosine kinase 1 predisposes to the onset of diabetes via promoting pancreatic beta-cell death in diet-induced obese mice. The FASEB Journal 27(10):4294-4304. 